\title{
A Cross-sectional Study on Occurrence of Medication Errors in Outpatient Pediatric Department of Public Sector Hospital, Lahore, Pakistan
}

\author{
Akbar Jamshaid ${ }^{1, *}$, Munir Abu Bakar', Shahzadi Komal', Masood Imran², Qamar-uz-Zaman Muhammad², \\ Gillani Ali Hassan ${ }^{3}$ \\ ${ }^{1}$ Department of Pharmaceutical Sciences, The Superior College, Lahore, PAKISTAN. \\ ${ }^{2}$ Department of Pharmacy, The Islamia University of Bahawalpur, Bahawalpur, PAKISTAN. \\ ${ }^{3}$ Department of Pharmacy Administration, School of Pharmacy Xi'an Jiaotong University China, CHINA.
}

Received: 12 September 2018;

Accepted: 23 November 2018

*Correspondence to:

Akbar Jamshaid,

Department of Pharmaceutical Sciences The Superior College, Lahore, PAKISTAN. Email:dr.jamshaidsheikh@gmail.com

Copyright: (1) the author(s),publisher and licensee Indian Academy of Pharmacists. This is an open-access article distributed under the terms of the Creative Commons Attribution Non-Commercial License, which permits unrestricted non-commercial use, distribution, and reproduction in any medium, provided the original work is properly cited.

\begin{abstract}
Background: The knowledge of medication errors is an essential prerequisite for better healthcare delivery. Medication errors are potential errors and impart a significant burden on patient quality of life as well as economic status. Objectives: The study was conducted with objective to determine the prevalence and nature of medication errors in pediatric out-patients and also to study their prescribing pattern. Methods: A quantitative cross-sectional study was conducted in Outpatient Pediatric Department of Public Sector Hospital, Lahore, Pakistan over a period of one month during which 240 prescriptions were evaluated to identify medication errors and prescribing pattern. Data was collected by using a self-designed data collection tool and analyzed using SPSS version 20. Results: Current study evaluated 240 outpatient prescription orders out of which 234 were found to have medication errors. Highest percentage of errors observed in studied population including prescription errors (missed prescriber and patient information) (86.8\%), prescribing errors $(7.6 \%)$ and dispensing errors (3.6\%) respectively. Upper Respiratory Tract Infection was the extensive complaint of majority of patients and the drugs of concern were mainly antibiotics, antihistamines, analgesics and anti-inflammatory and expectorants. Conclusion: The current detection of medication errors reveals about recurrent basis of prescribing errors in addition to prescription parts errors. These findings emphasizes that prescribers need to work in alliance with pharmacist to improve patient's quality of life in primary care.
\end{abstract}

Key words: Medication error, Pediatric, Outpatient, Prescription.

\section{INTRODUCTION}

Public safety is notably a growing health issue. ${ }^{[1]} \mathrm{A}$ medication error is a preventable incident related with improper medication usage that can be managed through efficacious control system. ${ }^{[2]}$ In all health care settings the preventable medication errors account to have significant influence on more than 7 million patients with annual cost of USD 21 billion. $^{[3]}$ An estimated annual death rate of people in United States reported in a recent study in an Institute of Medicine is about 44000 to 98000 as consequence of medication related problems. ${ }^{[4]}$ Adverse drug event is the major concern frequently observed with medication errors that resulted in a surprisingly increased death rate from 20 to about 200 percent annually in UK from $1990-2000 \cdot{ }^{[5]}$ Drug is a predominant element in health care and play critical role in life saving. The improper medicine use has severe economical and health burden on society. Most extensively prescribing pattern found to be involved in such errors. ${ }^{[6]}$ Practice of hand written prescription is usually a significant factor related with occurrence of medication errors in outpatient settings. ${ }^{[7]}$ Due to lack of e-prescribing and less regulated non-hospital setting procedures, outpatients are more vulnerable to medication errors.

A considerable approach has been entitled to eradicate these errors and associated ADEs in adults but comparatively, it is hard to find published data about pediatric affairs ${ }^{[8]}$ In pediatric ambulatory patients drug use is one of the distinctive problem in assessment and regulation of disease because therapeutics dosage regimen is burdensome. ${ }^{[6]}$ Non provision of dosing on weight basis, poor communication and immature renal and hepatic physiology are the factors which make pediatric population more prone to these errors. ${ }^{[9]}$ A large number of health care settings in Pakistan are not equipped with appropriate e-prescribing system and are also burdened with huge patient flow thus; accordingly the current study was designed to look for occurrence of medication errors in prescription orders of ambulatory setting in Pakistan.

\section{MATERIALS AND METHODS}

A quantitative cross-sectional study was conducted in outpatient Pediatric Department of Public Sector Hospital Lahore, Pakistan. The data of 240 prescription order of patients up to 14 years of age over a period of one month from December, 2017 to January, 2018 was collected. Patients were approached by convenient sampling technique and their prescriptions were noted on a self-designed study questionnaire. Study questionnaire comprised of three sections. In Section I demographic characters of participants were noted, in section II we investigated about prescriber and patient information and section III gathers information about prescribing (drug name, route of administration, dose and frequency) and dispensing errors. BNF for Children 2014 was used for the reference to document. The data was analyzed by using SPSS version 20. 


\section{Inclusion and Exclusion Criteria}

All the children of age up to 14 years were included in this study.

The prescription with 2 or more drugs.

All the patients who visited for the first time.

\section{Ethical Approval}

This study was approved by the research and ethics committee of department of Pharmaceutical Sciences, Superior University Lahore and approval was also taken from Medical Superintendent of hospital. A verbal and written consent was taken from the parents or guardian of the patient.

\section{RESULTS}

In the current study a total of 274 patients were approached out of which 240 showed willingness to participate in the study with a response rate of $87.6 \%$. Study results revealed that maximum number of patients $(33.3 \%)$ were in between age categories of 4-6 years followed by 1-3 years $(29.0 \%)$, 7-11 years (25.3\%) and 12-14 years (12.0\%) respectively (Figure 1). Regarding gender distribution female ratio was slightly higher (50.4\%) than the males. A large number of the pediatric ambulatory patient were with weight $15-22 \mathrm{~kg}$ $(35.0 \%)$ followed by $7-14 \mathrm{~kg}(34.6 \%), 23-30 \mathrm{~kg}(19.2 \%)$ and $31-38 \mathrm{~kg}(11.3 \%)$ respectively (Table 1$)$.

Substantial drugs prescribed in concerned population were antibiotics 218 $(90.8 \%)$ followed by anti-cold formulations 199 (81.7\%), analgesics 154 $(64.2 \%)$, vitamin supplements $39(16.3 \%)$ and anti-histaminic $14(5.8 \%)$ respectively (Table 2) (Figure 2).

Out of total 240 prescriptions $234(97.5 \%)$ prescriptions had at least one type of medication error. In context to prescriber and patient information error doctors name was missing on $15(6.3 \%)$, date in 23 (9.6\%), patients name in $3(1.3 \%)$, patients age in $39(16.3 \%)$ and weight was missing in $67(27.9 \%)$ prescriptions. Similarly, in terms of prescribing errors drugs name was wrong in $17(7.5 \%)$ and route of administration was wrong in $43(17.9 \%)$ prescriptions. Dose and frequency of dose was high and low in $4(1.7 \%)$ and $5(2.1 \%)$ patients respectively (Table 3) (Figure 3 ).

\section{DISCUSSION}

A medication error is any event associated with medication that can be prevented by use of effective control system. Medication error can result

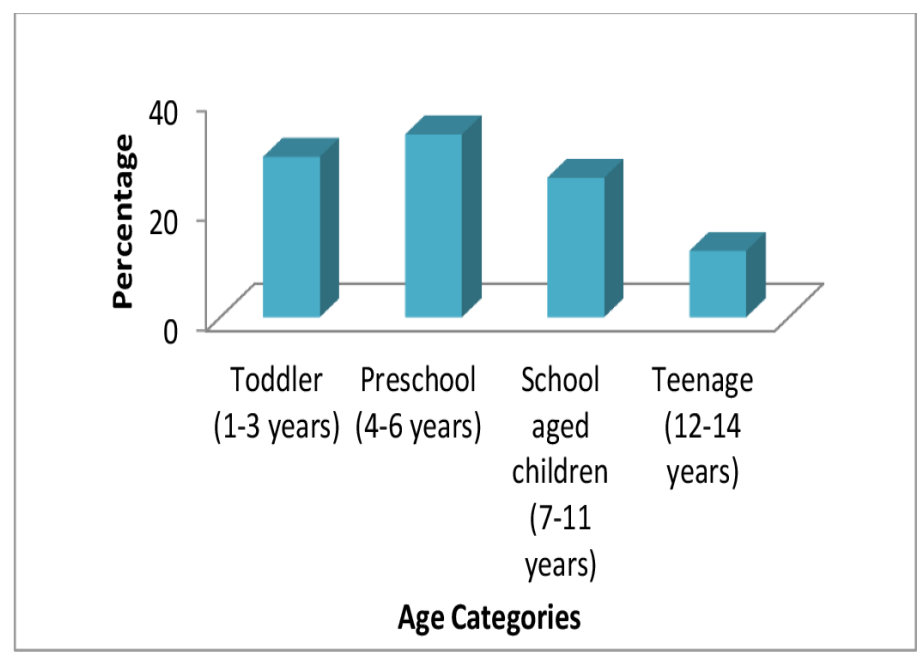

Figure 1: Distribution of patients according to the age group.

\begin{tabular}{|l|l|}
\hline \multicolumn{2}{|l|}{ Table 1: Gender Distribution. } \\
\hline Gender & N (\%) \\
\hline Male & $119(49.6)$ \\
\hline Female & $121(50.4)$ \\
\hline Total & $240(100)$ \\
\hline
\end{tabular}

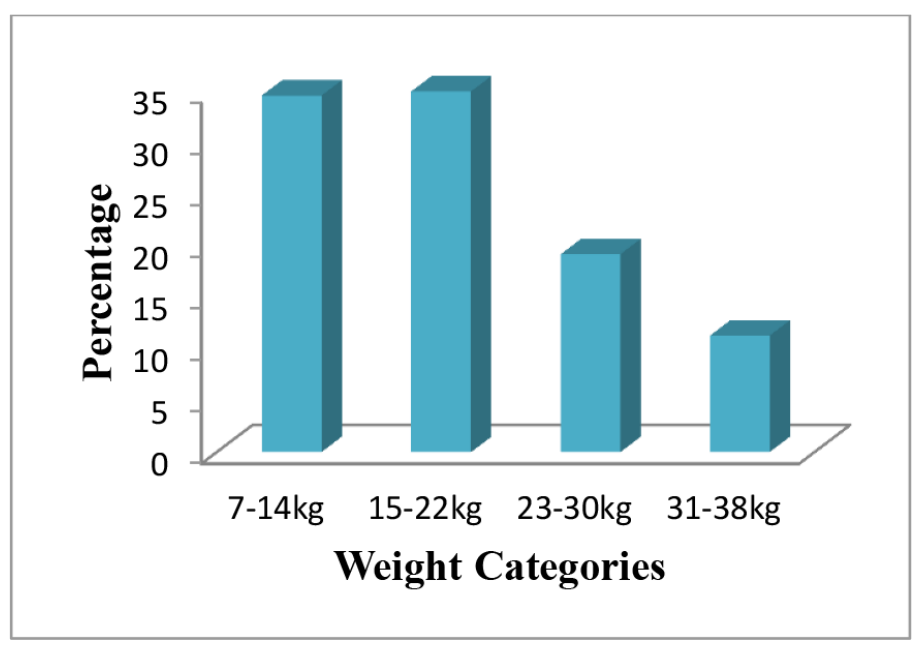

Figure 2: Distribution of patients according to the weight categories.

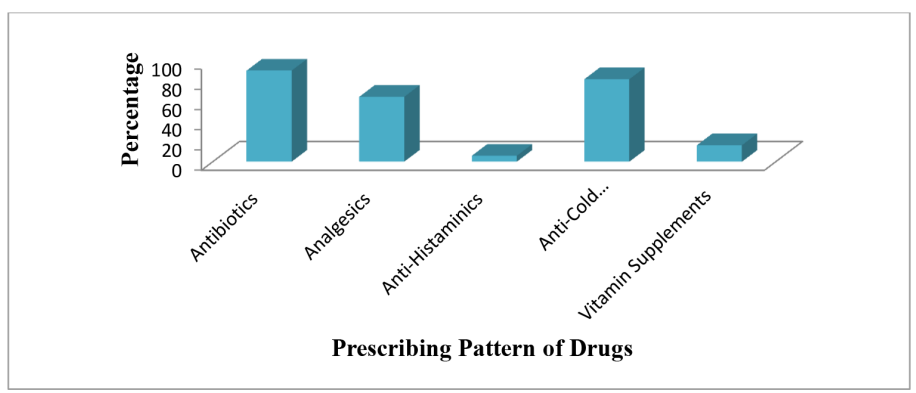

Figure 3: Prescribing framework of Drugs.

\begin{tabular}{|c|c|c|}
\hline Types of Medication errors & $\begin{array}{l}\text { Frequency of } \\
\text { errors }\end{array}$ & $\begin{array}{l}\text { Percentage } \\
(\%)\end{array}$ \\
\hline \multicolumn{3}{|l|}{$\begin{array}{l}\text { Prescriber and Patient Information } \\
\text { Doctor's name }\end{array}$} \\
\hline Date & 15 & 6.3 \\
\hline Patient's name & 23 & 9.6 \\
\hline Patient's age & 3 & 1.3 \\
\hline \multirow[t]{2}{*}{ Missing patient's weight } & 39 & 16.3 \\
\hline & 67 & 27.9 \\
\hline \multicolumn{3}{|l|}{ Prescribing Errors } \\
\hline Wrong drug's name & 17 & 7.5 \\
\hline Route of administration & 43 & 17.9 \\
\hline \multicolumn{3}{|l|}{ Dose error } \\
\hline Overdose & 4 & 1.7 \\
\hline Underdose & 5 & 2.1 \\
\hline \multicolumn{3}{|l|}{ Frequency error } \\
\hline High frequency & 4 & 1.7 \\
\hline Low frequency & 5 & 2.1 \\
\hline $\begin{array}{l}\text { Dispensing Error: } \\
\text { Incomplete or no drug information }\end{array}$ & 9 & 3.7 \\
\hline
\end{tabular}


in adverse drug reactions (ADRs), drug-drug interactions, lack of efficacy, suboptimal patient adherence and poor quality of life. In health care settings medication error is a recurrent cause of mortality and morbidity. ${ }^{[2,10]}$ They represent a severe social and health problem with important economic consequences. ${ }^{[11]}$ Medication errors exist in both developed and developing countries but in developing countries the condition is worse and need to be addressed. The current study looked for detection of the occurrence of medication errors among children. Results of study revealed much high frequency $(97.5 \%)$ of errors in studied population. These results are in accordance with the findings from study reported from other parts of Pakistan where the rate of prevalence of errors is also high (98\%). ${ }^{[12]}$ Similar to what is reported from Pakistan, high frequency of errors is also reported around the globe where in developing countries such as India, Nepal and Iran. ${ }^{[13-15]}$ Contrary to the recent finding, in the developed countries such as USA, Canada, Australia and New York the occurrence of medication errors is comparatively low $(70 \%){ }^{[16-19]}$ A possible major reason that can be attributed to this difference is their advanced health care system, other factors that can also be considered responsible for this difference can be demographic variation of the study population, study location and as well as the study tool used for data collection. ${ }^{[20]}$ Besides of medication related errors, incomplete prescription parts majorly prescriber and patient information presented with high percentage of errors that is in accordance with study of other regions of country. ${ }^{[21]}$ The slot for errors appears to be a greater extent owing to availability of lesser number of licensed drugs specifically tested for children and a deprivation of appropriate medication strengths in contrast to the adult community. ${ }^{[22]}$ Many variables for instance, weight, body surface area, age and health status of patients are basis to calculate sufficient Pediatric dosages. ${ }^{[22,23]}$ $40 \%$ of the errors are associated with care givers in dosing liquid medications in children. ${ }^{[24]}$ Unintended toxic effects because of overdosing and insufficient therapeutic effects are related with under dosing of antibiotics in PAEDS. ${ }^{[25]}$ "Five rights" of medication administration have crucial role to lessen the incidence of medication errors "the right drug, for the right patient, at the right time, in the right dosage, by the right route". ${ }^{[26]}$ The necessity to initiate rational and empirical protocols, physician need to work in alliance with clinical pharmacist to limit medication over prescribing. ${ }^{[27]}$ Significant training must be given to future prescribers and other healthcare professionals in college and universities together with awareness programs relevant to such error prevalence and harmful impact in society. Pharmacovigilance centers must be reinforced to notify healthcare professionals by revealing information about the numerous drug-related issues. This manifests that subsequent prevention can be attained to identify errors by pharmacist.

\section{CONCLUSION}

It comes to an end that the medication errors were frequently observed in pediatric ambulatory setting. Incorrect prescription writing and dispensing mainly attributed to insufficient time by prescribers to calculate appropriate doses in accordance with child's physiology. In spite of the fact that prescribing errors are familiar, prescription elements need to be addressed. Acceptable regulations and computerized prescription are required to minimize these errors.

\section{ACKNOWLEDGEMENT}

We acknowledge the great help from the staff of Outpatient Pediatric Department of Mayo Hospital, Lahore, Pakistan and also appreciate the participation of the patients.

\section{CONFLICT OF INTEREST}

The authors proclaim no conflicts of interest.

\section{ABBREVIATIONS}

e-Prescription: Electronic Prescription; ADEs: Adverse Drug Events; ADRS: Adverse Drug Reactions; PAEDS: Paediatric Active Enhanced Disease Surveillance; URTIs: Upper Respiratory Tract Infections.

\section{REFERENCES}

1. Kaushal R, Jaggi T, Walsh K, Fortescue EB, Bates DW. Pediatric Medication Errors: What Do We Know? What Gaps Remain?. Ambulatory Pediatrics. 2004;4(1):73-81.

2. Brennan TA, Leape LL, Laird NM, Hebert L, Localio AR, Lawthers AG, et al. Incidence of adverse events and negligence in hospitalized patients: results of the Harvard Medical Practice Study I. BMJ Quality and Safety. 2004;13(2):145-51.

3. Da Silva BA, Krishnamurthy M. The alarming reality of medication error: a patient case and review of Pennsylvania and National data. J Community Hospital Internal Medicine Perspectives. 2016;6(4):31758.

4. Donaldson MS, Corrigan JM, Kohn LT. To err is human: building a safer health system: National Academies Press. 2000.

5. Aronson JK. Medication errors: what they are, how they happen and how to avoid them. QJM. 2009;102(8):513-21.

6. Agalu A, Mekonnen H. Drug prescribing practice in a pediatrics ward in Ethiopian. Int Res J Pharm Pharmacol. 2012;2(6):132-8.

7. Cypress BK. Drug utilization in office visits to primary care physicians: national ambulatory medical care survey.1980: Citeseer. 1982.

8. Fortescue EB, Kaushal R, Landrigan CP, McKenna KJ, Clapp MD, Federico F, et al. Prioritizing strategies for preventing medication errors and adverse drug events in pediatric inpatients. Pediatrics. 2003;111(4):722-9.

9. Kaushal R, Goldmann DA, Keohane CA, Abramson EL, Woolf S, Yoon C, et al. Medication errors in paediatric outpatients. BMJ Quality and Safety. 2010;qshc-2008.

10. Brennan TA, Leape LL, Laird NM, Hebert L, Localio AR, Lawthers AG, et al. Incidence of adverse events and negligence in hospitalized patients: results of the Harvard Medical Practice Study I. New England J Med. 1991;324(6):370-6.

11. Barber N, Dean B. The incidence of medication errors and ways to reduce them. AVMA Medical and Legal Journal. 1998;4(4):103-6.

12. Afridi U. Medication Errors Assessment and Prevention by a Clinical Pharmacist in Pediatric Wards of RMI Hospital Peshawar, KPK-Pakistan. Ann Pak Inst Med Sci. 2015;11(3):124-9.

13. Mansouri A, Ahmadvand A, Hadjibabaie M, Kargar M, Javadi M, Gholami K. Types and severity of medication errors in Iran; a review of the current literature. Daru. 2013;21(1):49.

14. Aneja S, Bajaj G, Mehandiratta S. Errors in medication in a pediatric ward. Indian Pediatrics. 1992;29(6):727-30.

15. Ansari M, Neupane D. Study on determination of errors in prescription writing: A semielectronic perspective. Kathmandu University Med J. 2009;7(3):238-41.

16. Roughead EE, Semple SJ. Medication safety in acute care in Australia: where are we now? Part 1: a review of the extent and causes of medication problems 2002-2008. Australia and New Zealand Health Policy. 2009;6(1):18.

17. DeDonato EA, Spiller HA, Casavant MJ, Chounthirath T, Hodges NL, Smith GA. Nonhealth care facility anticonvulsant medication errors in the United States. Hum Exp Toxicol. 2017;37(6):561-70.

18. Pharmacists ASoH-S. ASHP guidelines on preventing medication errors in hospitals. Am J Health-System Pharm. 1993;50(2):305-14.

19. Cowley E, Williams R, Cousins D. Medication errors in children: a descriptive summary of medication error reports submitted to the United States Pharmacopeia. Current Therapeutic Res. 2001;62(9):627-40.

20. UI Haq N, Hassali MA, Shafie AA, Saleem F, Farooqui M, Aljadhey H. A cross sectional assessment of knowledge, attitude and practice towards Hepatitis $\mathrm{B}$ among healthy population of Quetta, Pakistan. BMC Public Health. 2012;12(1):692.

21. Mohammad IS, Khan H, Akhtar N, Saqib N, Rasool F, ljaz H. Significance of prescription elements and reasons of prescription errors in South Punjab, Pakistan. World Appl Sci J. 2015;33:668-72.

22. Chua SS, Chua HM, Omar A. Drug administration errors in paediatric wards: a direct observation approach. European J Pedia. 2010;169(5):603-11. 
23. Stewart M, Purdy J, Kennedy N, Burns A. An inter professional approach to improving paediatric medication safety. BMC Medical Education. 2010;10(1):19.

24. Yin HS, Dreyer BP, Moreira HA, Schaick LV, Rodriguez L, Boettger S, et al. Liquid medication dosing errors in children: role of provider counseling strategies. Academic Pediatrics. 2014;14(3):262-70.

25. Perwitasari DA, Abror J, Wahyuningsih I. Medication errors in outpatients of a government hospital in Yogyakarta Indonesia. Int J Pharm Sci Res Review. 2010;1(1):8-10.
26. Mc Donnell C. Opioid medication errors in pediatric practice: four years' experience of voluntary safety reporting. Pain Research and Management. 2011;16(2):93-8.

27. Fekadu H. Assessment of prescribing and adminstration errors in pediatric inpatients in black lion specialized hospital and zewditu memorial hospital, addis ababa, ethiopia: Addis Ababa University Addis Ababa, Ethiopia. 2013. Available from: http://etd.aau.edu.et/bitstream/handle/123456789/1850/Hamrawit\%20Fekadu. pdf?sequence=1\&isAllowed=y

Cite this article as: Jamshaid A, Bakar MA, Komal S, Imran M, Muhammad Q, Hassan GA. A Cross-sectional Study on Occurrence of Medication Errors in Outpatient Pediatric Department of Public Sector Hospital, Lahore, Pakistan. J Pharm Pract Community Med. 2018;4(4):207-10. 